\title{
BALANÇO DE ONDAS CURTAS SOBRE FLORESTA SAZONALMENTE ALAGÁVEL DO PANTANAL MATO-GROSSENSE
}

\author{
QUERINO, Carlos Alexandre Santos - carlosquerino@gmail.com \\ Universidade Federal do Amazonas - UFAM \\ BIUDES, Marcelo Sacardi - marcelo@fisica.ufmt.br \\ Universidade Federal de Mato Grosso - UFMT
MACHADO, Nadja Gomes - nadja.machado@blv.ifmt.edu.br Instituto Federal de Mato Grosso - IFMT

QUERINO, Juliane Kayse A. da Silva - julianekayse@hotmail.com Universidade Federal do Amazonas - UFAM

SANTOS NETO, Luiz Alves - luiz.santos@sipam.gov.br Sistema de Proteção da Amazônia - SIPAM
SILVA, Marcelo José Gama - marcelo.gama@sipam.gov.br Sistema de Proteção da Amazônia - SIPAM

ARRUDA, Paulo - paulo.zanella@fisica.ufmt.br Universidade Federal de Mato Grosso - UFMT

NOGUEIRA, José - nogueira@ufmt.br

Universidade Federal de Mato Grosso - UFMT

\begin{abstract}
RESUMO: A determinação e o entendimento do Balanço de Ondas Curtas (BOC) na interface biosfera-atmosfera é fundamental para se entender os principais processos de ordem física, química e biológica na superfície terrestre. O objetivo desse trabalho foi analisar a radiação solar global, o albedo superficial e o balanço de ondas curtas sobre uma área sazonalmente alagável no Pantanal. Os dados foram coletados em uma torre micrometeorológica instalada no Centro Avançado de Pesquisas da Universidade Federal do Mato Grosso, no Parque Baía das Pedras da Estância Ecológica SESC - Pantanal, entre novembro de 2013 até outubro de 2014. Houve influência direta do regime pluviométrico em todas as variáveis durante o período de estudo. A menor quantidade de precipitação durante a estação chuvosa e a maior durante a estação seca, em relação a normal climatológica, proporcionaram redução e aumento, respectivamente, na radiação solar incidente. Outra consequência do déficit pluviométrico na estação chuvosa e da anomalia positiva da precipitação na estação seca foi a inversão do albedo superficial entre as estações. As maiores médias do albedo superficial ocorreram durante a estação chuvosa e as menores na estação seca. A radiação solar incidente teve menor média durante o período vespertino que no período matutino ao longo de todo ano, o que indica que houve uma intensificação na formação de nuvens no período vespertino na região. Por fim, ressalta-se que o BOC foi fortemente influenciado pela variação sazonal e horária, tanto das componentes da radiação solar incidente quanto refletida.
\end{abstract}

Palavras- chaves: Radiação Solar Global, Albedo, Balanço Radiativo.

SHORT WAVE BALANCE OVER A SEASONALLY FLOODED FOREST OF THE PANTANAL IN THE MATO GROSSO STATE

ABSTRACT: To determine and understand the short wave balance on the biosphereatmosphere interface is elementary to comprehend the main physical, chemical and biological processes occurred on the Earth surface. The main aim of this paper was to 
analyze the incoming solar radiation, surface albedo, and the short wave balance over a seasonally flooded area in Pantanal. The data were collected in a micrometeorological tower installed in the Advanced Research Center of the Federal University of Mato Grosso, in the Baia das Pedras Park and placed in the Ecological Stanza SESC Pantanal, throughout November 2013 and October 2014. In the study period was observed a direct influence of the rainfall in all variables. The lowest amount of rain through the rainy season and the high register of rain through the dry season, when compared to the climatological reference, results in a reduction/increase, respectively, of the total amount of the incoming solar radiation. Furthermore, the rainfall deficit in the rainy season and the positive anomaly of the rain in the dry season was the inversion on the surface albedo value when compared values among the seasons. The highest albedo values were observed in the wet season, in while the lowest in the dry season. On the daily cycle was observed that the $R_{g}$ tends to be lowest during the afternoon period through the entire year, which implies that there was an increase on the cloud formation on that region in the afternoon. Lastly, we highlight that the BOC was strongly influenced by the seasonal and hourly variation such as the incoming as the reflected radiation.

Keywords: Income Solar Radiation, Albedo, Radiation Balance.

\section{INTRODUÇÃO}

O Pantanal localiza-se no centro da América do Sul, conhecido como a maior floresta alagável do mundo, e possuir uma rica biodiversidade de flora e fauna (BIUDES et al., 2015; MACHADO et al., 2016). O Pantanal é um mosaico composto pela floresta Amazônica, Cerrado e Chacos bolivianos e Paraguaios (JUNK e NUNES DA CUNHA, 2005). Devido à importância, tanto de ordem biológica, ecológica ou climática do Pantanal, inúmeras pesquisas nos mais diversos contextos vêm sendo realizadas em toda a região. Em termos climáticos, o principal foco das pesquisas é entender como ocorrem os processos de troca de energia entre a superfície pantaneira e atmosfera (BIUDES et al., 2015; MACHADO et al., 2016). Essas trocas de energia, depende dentre outros fatores, da quantidade de radiação solar que incide e como ela interage com a superfície.

A Radiação Solar Global $\left(R_{g}\right)$ é considerada a principal fonte de energia natural no sistema terra-atmosfera capaz de influenciar nos processos atmosféricos, e consequentemente, nas condições de tempo e clima da Terra, pois é responsável pelos principais processos de ordem física, química e biológica (SOUZA et al., 2005; GUSMÃO et al., 2012). O comprimento de onda da $R_{g}$ dentro do espectro eletromagnético está na faixa de 0,3 a 4,0 $\mu \mathrm{m}$, o que a classifica como ondas curtas (GOMES et al., 2009). A compreensão entre a quantidade de radiação de ondas curtas que entra $\left(R_{g}\right)$ e sai por reflexão $\left(R_{g \_}\right.$Ref $)$ na interface biosfera-atmosfera é fundamental para se entender as trocas radiativas que ocorrem nesta camada (INAMDAR e GUILLEVIC, 2015).

O coeficiente de reflexão da superfície da radiação de onda curta, isto é, a razão entre a $R_{g}$ e a $R_{g \_ \text {Ref }}$ sobre uma determinada superfície, é definido como albedo (a) (QUERINO et al., 2006; QUERINO et al., 2013). A determinação do a é importante, por exemplo, em estudo que procurem parametrizar balanço radiativo sobre superfície vegetadas (MOURA et al., 1999). A variação no a implicará em alteração no microclima local, uma vez que causará alteração na quantidade de energia que é armazenada na interface biosfera-atmosfera, a qual pode ser determinada pelo Balanço de Ondas Curtas (BOC) dessa superfície (KUSHARI e KANITPONG, 2001; INAMDAR e GUILLEVIC, 2015). 
O BOC é a análise das componentes de ondas curtas que entram e saem no sistema terra-atmosfera (GOMES et al., 2009). Qualquer alteração que ocorra no fluxo radiativo entre a superfície e a atmosfera modificará suas condições térmicas, bem como a circulação atmosférica (CUI et al., 2012). Então, a determinação e o entendimento do BOC sobre certa região é fundamental para se entender processos como o de aquecimento do solo e do ar, a fotossíntese, a evaporação e a evapotranspiração (CUI et al., 2012; GUSMÃO et al., 2012).

Praticamente é inexistente estudos sobre o BOC em qualquer área do Pantanal brasileiro. Existem alguns estudos que avaliaram a variação espacial do albedo no Pantanal utilizando imagens de satélite, mas nenhum estudo avaliou a sazonalidade das medidas da radiação do BOC e do a, localmente, por um período de um ano. Diante disso, o objetivo desse trabalho foi avaliar as séries da radiação solar global, do albedo superficial e do balanço de ondas curtas sobre uma área sazonalmente alagável no Pantanal.

\section{MATERIAL E MÉTODO}

\subsection{DESCRIÇÃO DA ÁREA DE ESTUdO}

O experimento foi realizado dentro de uma área de preservação pertencente ao Centro Avançado de Pesquisas da Universidade Federal do Mato Grosso, no Parque Baía das Pedras da Estância Ecológica SESC - Pantanal, localizado no município de Poconé, Pantanal mato-grossense e distante aproximadamente $160 \mathrm{~km}$ da capital Cuiabá (Figura 1). A região caracteriza-se por ser uma área plana de solo hidromórfico onde ocorre inundação, com predominância de argila na área de estudo (CORINGA et al., 2012; MACHADO et al., 2015). A vegetação predominante é a Combretum lanceolatum Pohl, localmente chamada de "Pombeiral", marcada por pequenas árvores e pequenos arbustos (BIUDES et al., 2015).

A área caracteriza-se por apresentar uma complexa variabilidade climática, principalmente nas temperaturas e precipitação (ALVES, 2009). De acordo com a classificação de Köppen, o clima é Aw, ou seja, quente e úmido, com precipitação elevada no verão (estação chuvosa), déficit pluviométrico (estação seca) no inverno e um total anual da ordem de $1400 \mathrm{~mm}$ (MACHADO et al., 2015). As médias das temperaturas máximas anual variam entre 29 e $32^{\circ} \mathrm{C}$, enquanto que as médias das temperaturas mínimas anual oscilam entre 17 e $20^{\circ} \mathrm{C}$ (BIUDES et al., 2012; 2014). Maiores detalhes sobre a climatologia local e os principais sistemas atmosféricos que agem sobre a região podem ser encontrados em MACHADO et al. (2015) e QUERINO (2016) 


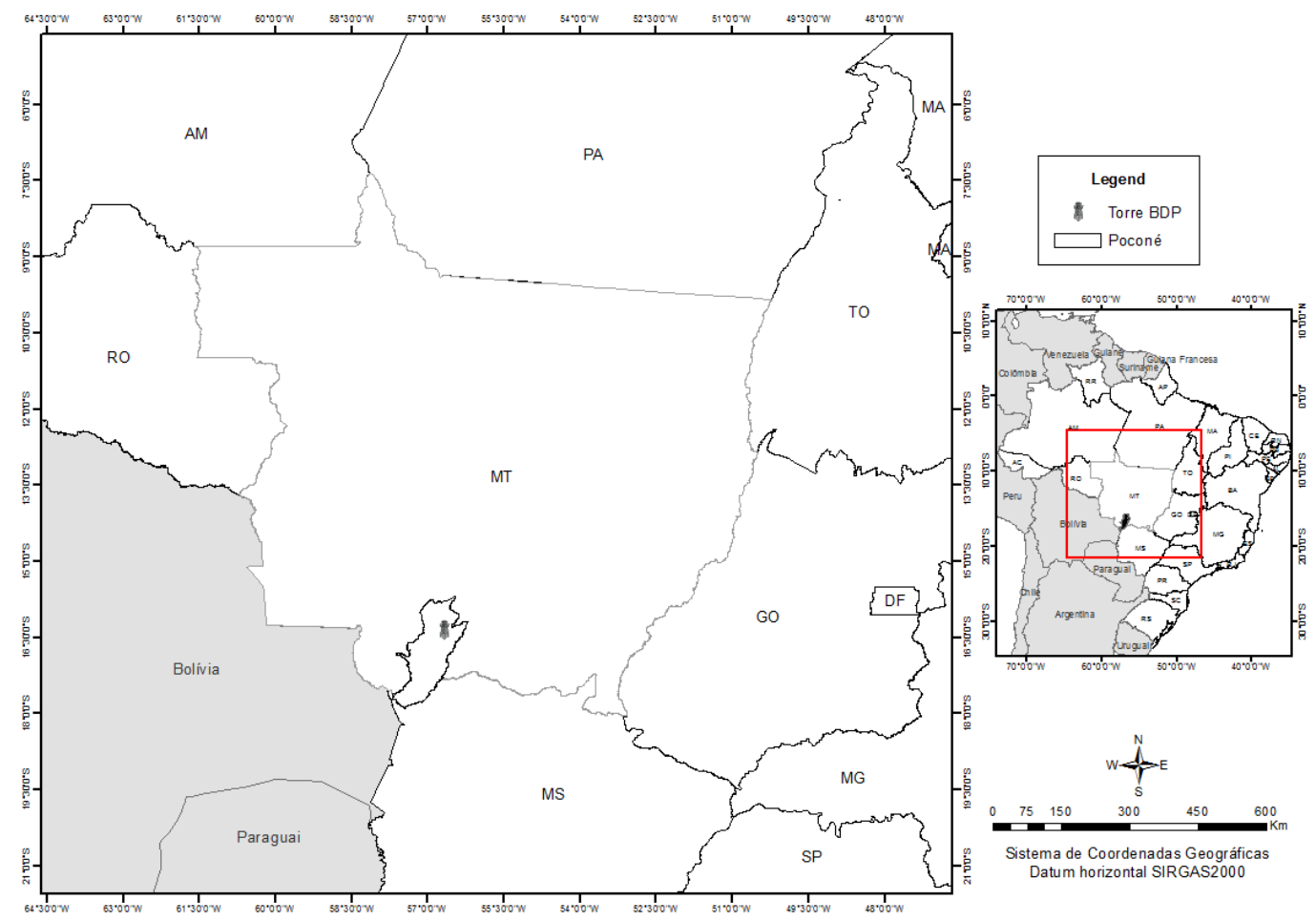

Figura 1 - Localização do município de Poconé, Pantanal mato-grossense, onde se encontra instalada a torre de medidas micrometeorológica na Estância Ecológica do Parque Baía das Pedras, SESC - Pantanal.

\section{2 - AQUISIÇÃO DOS DADOS METEOROLÓGICOS}

Os dados de Radiação Solar Global Incidente $\left(R_{g}\right)$ e Refletida $\left(R_{g_{-} R e f}\right)$ foram medidas por piranômetros (LI200X, LI-COR, Lincoln, NE, USA) e a Precipitação (Ppt) foi medida por um pluviômetro (TB4 Campbell Sci., Logan, UT, USA) instalados a $20 \mathrm{~m}$ de altura em uma torre micrometeorológica ( $16^{\circ} 29^{\prime}$ $53.52^{\prime \prime} \mathrm{S}$ e $56^{\circ} 24^{\prime} 46.23^{\prime \prime} \mathrm{W}$ ). Os sensores foram lidos a cada 10 segundos e os dados foram armazenados em médias a cada 30 minutos em um registrador eletrônico (CR1000, Cambpell Scientific Inc., Logan, UT, USA).

As medidas foram realizadas entre novembro de 2013 e outubro de 2014, o que permitiu analisar as estações chuvosa e seca dentro de um mesmo ano hidrológico. Todos os sensores foram previamente calibrados no laboratório de instrumentação micrometeorológica do Programa de Pós-Graduação em Física Ambiental - PPGFA, da Universidade Federal do Mato Grosso antes de serem colocados em campo.

Como a região do sítio experimental Baía das Pedras (BDP) não possui série histórica, utilizou-se como referência a normal climatológica do município de Cuiabá - MT, entre os anos de 1960 e 1990, fornecida pelo Instituto Nacional de Meteorologia - INMET. O sítio experimental BDP, está distante aproximadamente $160 \mathrm{~km}$ de Cuiabá, representando assim a área de cobertura de uma estação meteorológica. Esse critério foi definido de acordo com o manual da Organização Meteorológica Mundial (OMM) n.o 544, 2003, no qual 
estabelece que o intervalo horizontal entre estações, em geral, não deve exceder 250 km, ou $300 \mathrm{~km}$ em regiões pouco povoadas (WMO, 2003).

\section{3 - PROCESSAMENTOS DOS DADOS}

Os dados medidos foram processados em médias horárias, mensais e sazonais, além de serem separados em estações seca e chuvosa. O albedo (a) foi estimado seguindo a definição da variável, que é o quociente entre a Radiação Global Refletida $\left(\mathrm{R}_{\mathrm{g}_{-} \text {Ref }} ; \mathrm{W} \mathrm{m}^{-2}\right)$ e a Incidente $\left(\mathrm{R}_{\mathrm{g}} ; \mathrm{W} \mathrm{m}^{-2}\right)$ (Equação 1 ) (GOMES et al., 2009).

$\alpha=\frac{R_{g_{-} R e f}}{R_{g}}$

A estimativa do BOC foi realizada por meio da diferença entre o total de $\mathrm{R}_{\mathrm{g}}$ que atinge a superfície e o montante refletido pela mesma (a) (Equação 2) (GOMES et al., 2009).

$B O C=R_{g} *(1-\alpha)$

\section{RESULTADOS E DISCUSSÃO}

\subsection{PRECIPITAÇÃO}

A precipitação na área de estudo apresentou total anual pluviométrico $(1327,8 \mathrm{~mm})$ dentro dos padrões climatológicos $(1342,3 \mathrm{~mm})$. A diferença de $14,5 \mathrm{~mm}$ indica que o ano ocorreu dentro dos padrões normais. No entanto, a estação chuvosa registrou déficit pluviométrico de $136,6 \mathrm{~mm}$ em relação à normal climatológica. Apesar da estação chuvosa ter apresentado valores abaixo da média, a precipitação na estação seca foi $121,8 \mathrm{~mm}$ maior do que da normal climatológica.. 


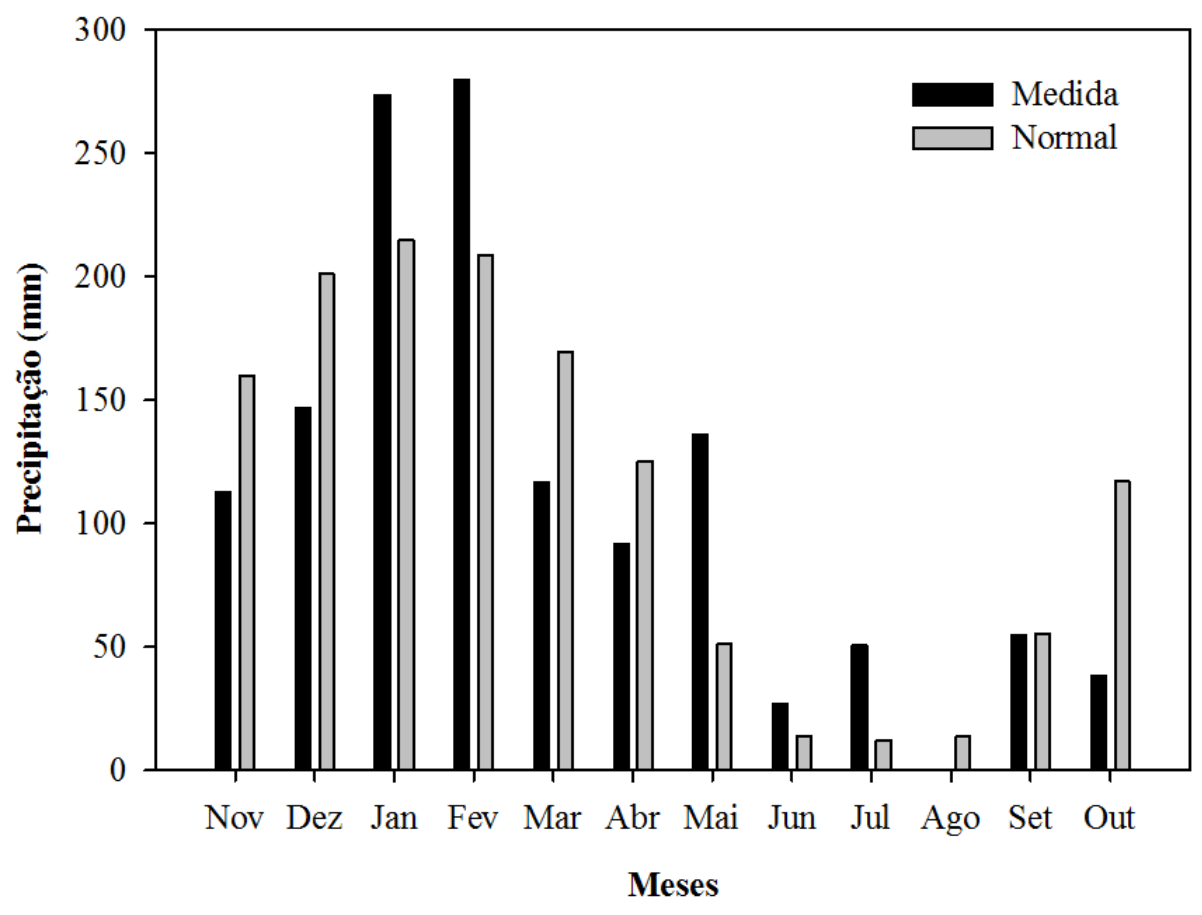

Figura 2 - Total pluviométrico mensal, medido no sítio experimental Baía da Pedra (BDP) e normal climatológica para o município de Cuiabá - MT (1960 - 1990) fornecida pelo Instituto Nacional de Meteorologia - INMET.

Essa anomalia positiva de precipitação durante a estação seca foi devido à atuação de cavados em níveis médios da atmosfera, a intensificação dos Jatos de Baixos Níveis (JBN) a leste dos Andes e ao avanço de sistemas frontais nos meses de maio, junho e julho (ESCOBAR, 2014a; 2014b; 2014c). A atuação desses sistemas atmosféricos fizeram com que os totais pluviométricos de maio, junho e julho, juntos excedessem em 2,7 vezes o total pluviométrico esperado para esses meses $(213,4 \mathrm{~mm}$ registrado e $77,1 \mathrm{~mm}$ esperados pela normal). No entanto, houve uma anomalia negativa de $13 \mathrm{~mm}$ durante o mês de agosto e em setembro houve comportamento de acordo com a normal climatológica com aproximadamente $55 \mathrm{~mm}$ de chuvas registrados ao longo de todo o mês.

A precipitação em novembro de 2013 e março e abril de 2014 contribuíram para a anomalia negativa de precipitação durante a estação chuvosa, por apresentarem déficit pluviométrico. Contudo, houve anomalias positivas de precipitação em janeiro e fevereiro de 2014. Em janeiro, as anomalias de precipitação estão relacionadas a um episódio de Zona de Convergência do Atlântico Sul (ZCAS) que se estabeleceu por alguns dias durante a segunda quinzena do mês e organizou máximos movimentos verticais ascendentes e máximas divergências de vento em altos níveis da atmosfera, ocasionando, na região de estudo, os maiores volumes de chuva (CPTEC/INPE, 2014). Em fevereiro, a quebra do bloqueio atmosférico na segunda quinzena do mês favoreceu o retorno da Alta da Bolívia $(A B)$ e do Vórtice Ciclônico de Altos Níveis (VCAN) às suas posições climatológicas e permitiu a organização de 3 
episódios de ZCAS apenas nesse período, elevando os volumes de chuva na região de estudo (GPT, 2014).

O regime pluviométrico da região é governado principalmente por fenômenos de larga escala, como a atuação da AB, ZCAS e Sistemas Frontais (ALVES, 2009; MACHADO et al., 2015). A AB apresenta-se como um anticiclone em altos níveis da atmosfera originado devido ao forte aquecimento convectivo superficial (liberação de calor latente) e formação de nuvens convectivas geradoras de tempestades (ALVES, 2009). Já a ZCAS caracteriza-se pela formação de nebulosidade intensa, orientada no sentido noroeste-sudeste, estendendo-se da Amazônia até o sudoeste do Oceano Atlântico, influenciando as precipitações desde o centro-sul da Região Norte até o norte do Paraná (ESCOBAR, 2014d). No entanto, esses sistemas podem ter sua atuação inibida devido à ocorrência de fenômenos de larga escala, como os bloqueios atmosférico.

O bloqueio atmosférico é configurado quando as condições meteorológicas a ele associadas persistem durante dias (7-8 dias) e, em casos raros, podem chegar até 15 dias, modificando os padrões de precipitação e temperatura em uma ampla região (OLIVEIRA et al, 2014). Os anticiclones associados a bloqueios ocorrem normalmente nas latitudes médias, e em geral, sobre o Oceano Pacífico (OLIVEIRA, 2011). Em 2014 foi observada uma condição de bloqueio bastante intensa no sul da América do Sul que inibiu o avanço de frente frias, e reduziu a ocorrência de ZCAS, e consequentemente provocou a estiagem durante a estação chuvosa (MARENGO et al., 2015). Ainda segundo Marengo et al. (2015) esse sistema de alta pressão deixou o ar mais secos e estável, inibiu a formação de nuvens e ainda bloqueou a passagem dos sistemas frontais, inibindo também o transporte do fluxo de umidade oriundo da Amazônia.

\subsection{RADIAÇÃO SOLAR GLOBAL $\left(\mathbf{R}_{\mathbf{g}}\right)$}

A média anual $R_{\mathrm{g}}$ foi de $\sim 335 \mathrm{~W} \mathrm{~m}^{-2}$, com média durante a estação chuvosa ( $354 \mathrm{~W} \mathrm{~m}^{-2}$ ) 13\% maior que na estação seca $\left(\sim 308,43 \mathrm{~W} \mathrm{~m}^{-2}\right)$. Ao longo do ano, a menor média registrada ocorreu no mês de julho ( $261 \mathrm{~W} \mathrm{~m}^{-2}$ ) enquanto a maior foi em novembro ( $400 \mathrm{~W} \mathrm{~m}^{-2}$ ) (Figuras $3 a$ e $3 b$ ). Esse padrão da $\mathrm{Rg}$ da região é influenciado pelos fatores astronômicos e a cobertura de nuvens (BIUDES et al., 2012; 2015). A estação seca ocorre concomitante ao período de inverno no hemisfério sul, o que aumenta o ângulo de incidência dos raios solares no topo da atmosfera. Esse maior ângulo de incidência, por consequência, aumenta o caminho ótico percorrido até a superfície e aumenta a área de projeção da radiação, o que naturalmente reduz a quantidade de $R_{g}$ (IQBAL, 1983; QUERINO et al., 2011). Além do fator astronômico, a estação seca de 2014 foi marcada por chuvas acima da média, principalmente em maio, junho e julho, o que pode ter contribuído para o aumento de nuvens $e$ consequentemente uma maior atenuação da $R_{g}$ pela atmosfera. As nuvens funcionam como um dos principais moduladores do total de radiação que atinge a superfície, sendo responsáveis pelas reflexões múltiplas além da absorção da radiação solar na atmosfera (GU et al., 2001; SANCHES-ROMERO et al., 2014). 

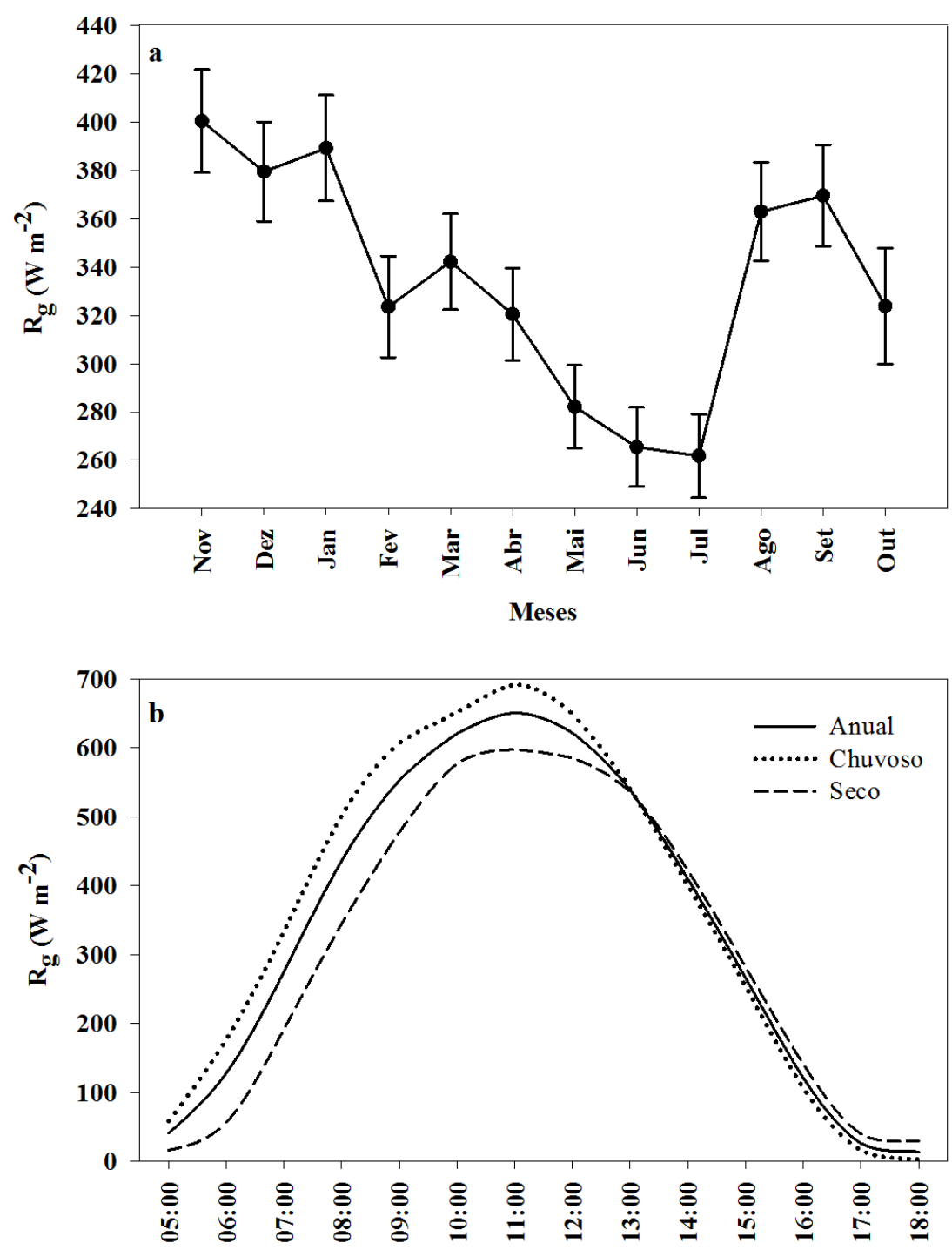

Hora Local

Figura 3: (a) Médias mensais ( \pm Intervalo de Confiança) e (b) médias horárias anual e nas estações chuvosa e seca da radiação solar incidente $\left(R_{g}\right)$ no sítio experimental Baía das Pedras, Pantanal Mato-Grossense entre novembro de 2013 até outubro de 2014.

A maior média da $\mathrm{R}_{\mathrm{g}}$ em novembro pode estar associada aos mesmos fatores, mas com consequências contrárias. Em novembro, os raios solares culminam sobre a região incidindo mais perpendicularmente. Além disso, a precipitação em novembro foi abaixo da normal climatológica, e possivelmente a concentração de nuvens também foi menor. A precipitação nesse mês provavelmente fez com que os aerossóis provenientes das queimadas durante 0 final da estação seca fosse decantados, tornando a atmosfera mais limpa, o que propiciou maior quantidade de radiação na superfície (MACHADO et al., 2016).

$A R_{g}$ durante o período vespertino foi menor do que no matutino (Figura 3b). A média do período matutino durante a estação chuvosa foi de $431 \mathrm{~W} \mathrm{~m}^{-2} \mathrm{e}$ no vespertino foi de $281 \mathrm{~W} \mathrm{~m}^{-2}$. Esse padrão se repetiu durante a estação seca, 
com médias de 323 e 290 W $\mathrm{m}^{-2}$ nos períodos matutino e vespertino, respectivamente. As menores médias de $\mathrm{Rg}$ durante o período vespertino podem estar associadas ao desenvolvimento de nuvens convectivas, cúmulos ou cumulonimbos nesse período. Esses tipos de nuvens são comuns em áreas de intenso calor superficial que favorece o transporte vertical turbulento de umidade (ANJOS et al., 2013). Esse transporte vertical ocorre devido ao desenvolvimento da Camada Limite Atmosférica (CLA), que se caracteriza por ligar a superfície terrestre com os altos níveis da atmosfera (NEVES e FISCH, 2011). O desenvolvimento da CLA no ciclo diário passa por uma fase de aprofundamento em poucas horas, ocasionando a formação das primeiras nuvens cúmulos por volta do meio dia, gerando o desenvolvimento de precipitação convectiva no período da tarde (BETTS et al., 2009). Assim, precipitação na área de estudo ocorre predominantemente durante o período vespertino.

\subsection{ALBEDO SUPERFICIAL (a)}

O albedo (a) médio anual da área de estudo foi 0,19 , com médias durante a estação chuvosa $(a=0,20) 11 \%$ maior que na estação seca ( $a=$ 0,18 ) (Figura 4a e 4c). Esses valores médios de a da área de estudo se assemelham aos encontrados em regiões de pastagem e floresta menos densa do que a floresta amazônica, como por exemplo, áreas de manguezais (QUERINO et al., 2006; 2013). Esses autores também observaram sazonalidade na série do a em suas áreas de estudo. O elevado valor de a pode estar relacionado ao tipo de vegetação e solo da área de estudo, que se caracteriza por ser uma área de solo argiloso, arbustiva e que sofre inundações sazonais (MACHADO et al., 2016).

Em geral, a sazonalidade do a é atribuída à mudança na cor da superfície (vegetação) decorrentes da mudança no conteúdo de água no solo (PAVÃO et al., 2015). Estudos realizados em áreas de floresta e pastagem na Amazônia, mostraram que em ambas as regiões o a diminuiu da estação seca para a chuvosa (MOURA et al., 1999). Dessa forma, esperou-se nesse estudo que o a durante a estação seca, fosse superior ao da estação chuvosa. No entanto, devido ao alto índice pluviométrico durante a estação seca, notou-se que o solo saturou, e alagou a área de medida a partir de fevereiro de 2014, mantendo-se nesta situação, até julho do mesmo ano (Figura 4b). Superfície mais escuras, assim como cobertas por água, tendem a refletir menos radiação, e por consequência, reduzir o valor do a (GIONGO et al., 2010; ANDRADE e CORRÊA, 2014). Os maiores valores de a durante a estação chuvosa estão relacionados a um solo mais seco, o que diminui a quantidade de folhas e sua coloração, e por consequência, eleva o a (QUERINO et al., 2016).

O a variou ao longo do dia com maiores valores ao nascer e pouco antes do pôr do sol, e menores valores próximo ao meio dia. Isso pode estar relacionado à forte dependência da radiação refletida com a inclinação dos raios incidente (QUERINO et al., 2006). Segundo esses autores, o albedo horário não está relacionado à quantidade de $\mathrm{R}_{\mathrm{g}}$, mas com o ângulo zenital local.

Não houve diferença entre as médias do a entre o período matutino e vespertino durante a estação seca $(a=0,16)$, o que caracteriza uma superfície bastante homogênea quanto a coloração, provavelmente por conta da lamina 
d'água nesse período. No entanto, o a durante a estação chuvosa foi cerca de $11 \%$ maior durante o período vespertino em relação ao matutino. Possivelmente isso ocorreu devido as chuvas convectivas que ocorrem no final tarde e início da noite. O volume de água precipitado pode umedecer o solo, deixa-lo úmido até o dia seguinte, e consequentemente, com uma coloração mais escura. Assim, no início da tarde a superfícies estaria mais seca e um pouco mais clara do que pela manhã.
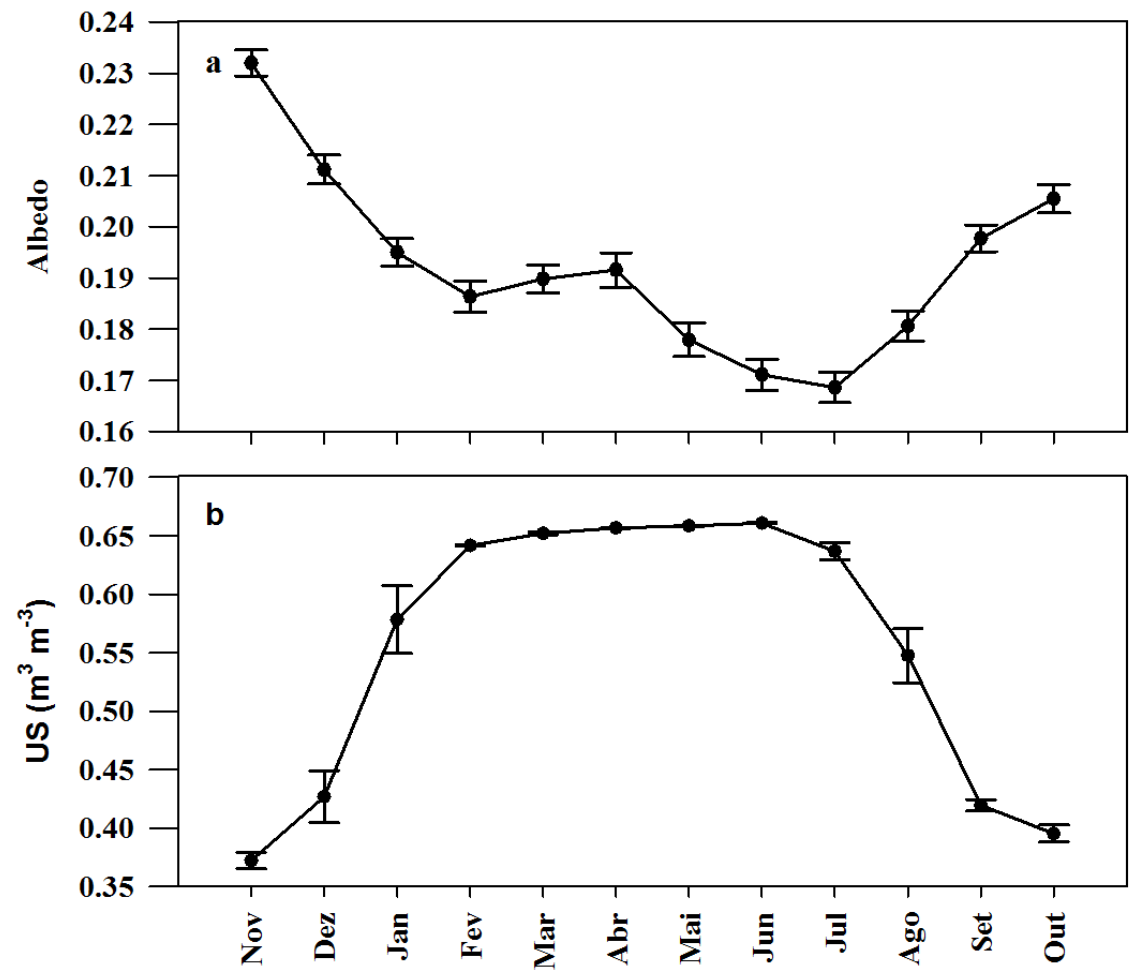

Meses

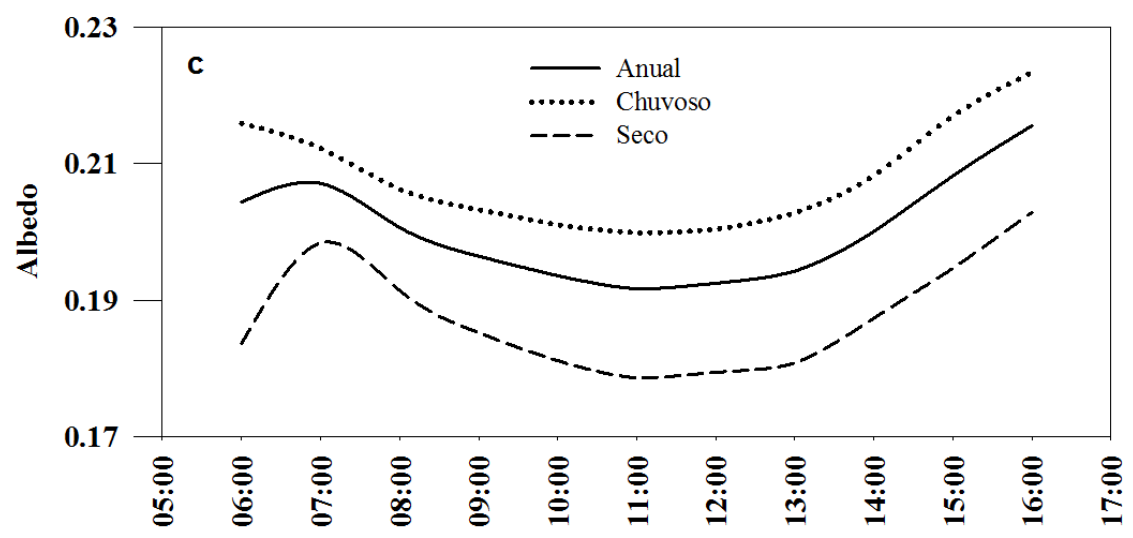

Hora Local

Figuras 4 - Médias mensais ( \pm Intervalo de Confiança) (a) do albedo e (b) da umidade do solo e (c) médias horárias anual e nas estações chuvosa e seca do albedo no sítio experimental Baía das Pedras, Pantanal Mato-Grossense entre novembro de 2013 até outubro de 2014. 


\subsection{BALANÇO DE ONDAS CURTAS (BOC)}

Um monitoramento preciso do BOC superficial é essencial para melhor compreensão do balanço de energia e ciclo hidrológico (INAMDAR e GUILLEVIC, 2015). A média geral do BOC durante todo o experimento foi de $293 \mathrm{~W} \mathrm{~m}^{-2}$. O BOC na estação chuvosa $\left(302 \mathrm{~W} \mathrm{~m}^{-2}\right.$ ) foi $7 \%$ maior que na estação seca ( $281 \mathrm{~W}$ $\mathrm{m}^{-2}$ ) (Figuras $5 a$ e $5 b$ ). A estação chuvosa é marcada por uma maior cobertura de nuvens, e consequentemente menor incidência de radiação solar na superfície (BETTS et al., 2009). No entanto, conforme foi discutido anteriormente, houve um déficit pluviométrico durante a estação chuvosa, o que provavelmente reduziu a quantidade de nuvens e elevou a quantidade de $R_{g}$, propiciando uma maior entrada de energia no sistema.
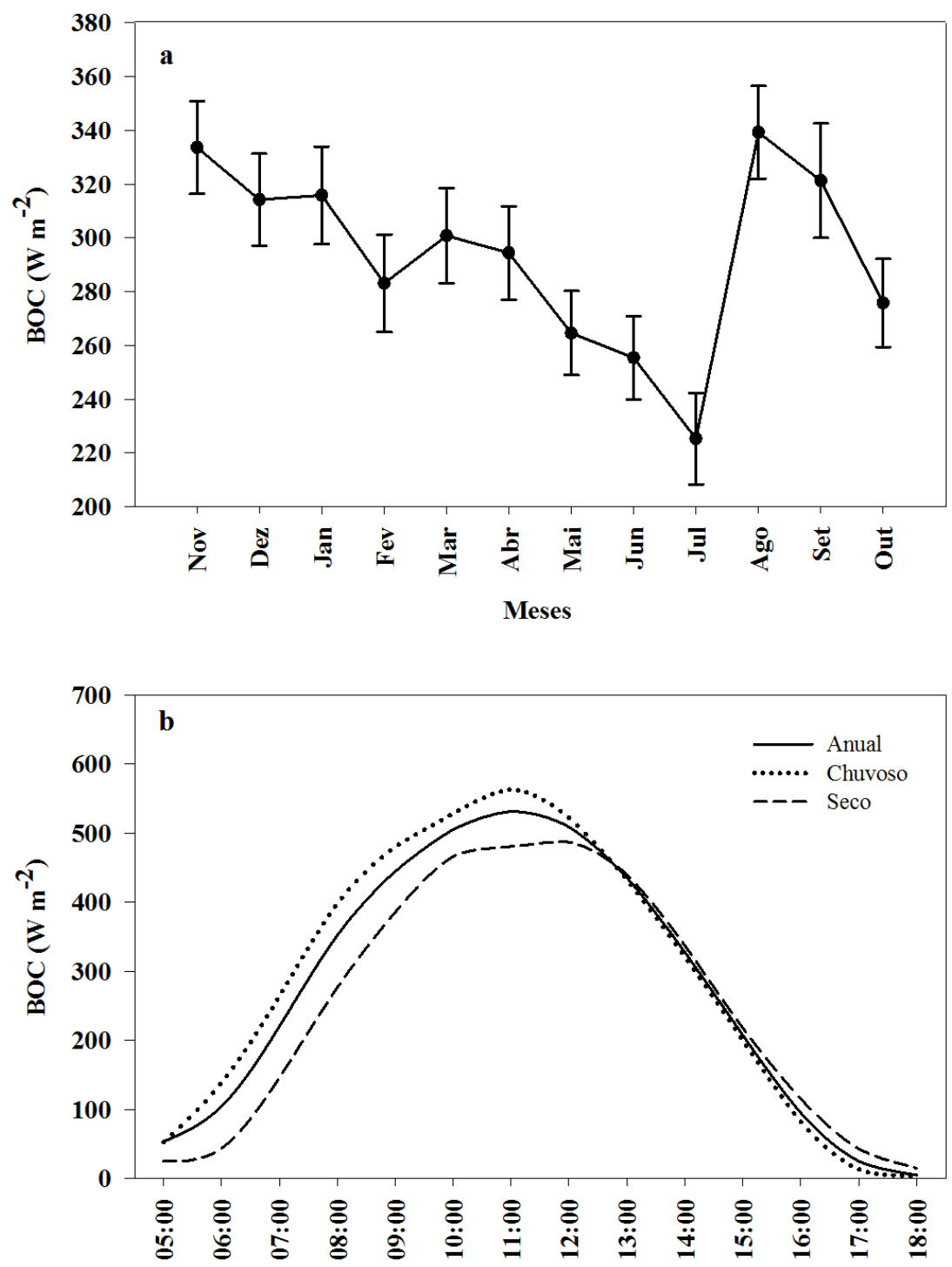

Hora Local

Figuras 5: Balanço de Ondas Curtas médio mensal (a) e comportamento médio horário, anual, da estação chuvosa e seca (b), para o sítio experimental Baía das Pedra - BDP, no período de novembro de 2013 a outubro de 2014. 
Apesar do maior a durante a estação chuvosa em relação a seca, a quantidade de energia que chegou à superfície também foi maior. Essa maior entrada de energia durante a estação chuvosa, possivelmente, resultou no maior BOC. No entanto, ambas as componentes do BOC reduziram durante a estação seca, contribuindo para menores valores de BOC. Contudo, a redução do a na estação seca foi peça chave na redução do BOC, uma vez que a alteração no a implica em modificações no BOC (INAMDAR e GUILLEVIC, 2015).

Assim como a $\mathrm{R}_{\mathrm{g}}$ a média do $\mathrm{BOC}$ na estação chuvosa foi menor durante o período vespertino (Figura $5 b$ ), enquanto que O BOC na estação seca praticamente não teve diferença entre o período matutino $\left(277 \mathrm{~W} \mathrm{~m}^{-2}\right) \mathrm{e}$ vespertino $\left(278 \mathrm{~W} \mathrm{~m}^{-2}\right.$ ). Como a média do a no período matutino e vespertino não diferenciaram durante a estação seca, o BOC também não variou, uma vez que $\mathrm{Rg}$ na estação seca apresentou pequena variação (INAMDAR e GUILLEVIC, 2015). A influência do a no BOC também foi observada por outros pesquisadores, que ao modelar o balanço de radiação em diferentes áreas e estações do ano, observaram que a variação no balanço radiativo foi devido ao a, tanto por mudança na cobertura superficial quanto entre as estações do ano (CUI et al., 2012).

\section{CONCLUSÕES}

Houve influência do regime pluviométrico em todas as variáveis analisadas. Por conta disso, $A R_{g}$ foi maior na estação chuvosa do que na estação seca. No ciclo diário, a $R_{g}$ tendeu a ser mais atenuada no período vespertino, independente da estação do ano.

Constatou-se que houve inversão do a entre as estações com maiores médias na estação chuvosa e menores na estação seca. Entre os períodos matutino e vespertino, o a não variou na estação seca, mas foi $11 \%$ maior no período vespertino que no período matutino na estação chuvosa.

Como consequência das variações de $R_{g}$ e a o BOC foi, também, fortemente influenciado pela variação sazonal e horária das componentes de radiação solar incidente e refletida.

\section{AGRADECIMENTOS}

A pesquisa foi apoiada pela Universidade Federal de Mato Grosso (UFMT), Instituto Federal de Mato Grosso (IFMT), Universidade Federal do Amazonas (UFAM), Programa de Pós Graduação em Física Ambiental (PPGFA/IF/UFMT) e Conselho Nacional de Desenvolvimento Científico e Tecnológico (CNPq) (CNPq Bolsas, Processo no 303625/2015-5), e financiada pela Fundação de Amparo à Pesquisa do Estado de Mato Grosso (FAPEMAT - PRONEM 2014, processo no 561397/2014). 


\section{REFERÊNCIAS BIBLIOGRÁFICAS}

ALVES, L. M. Clima da região centro-oeste do Brasil. In: CAVALCANTI, I. F. D. A., et al. Tempo e Clima no Brasil. São Paulo: Oficina de Textos, 2009. Cap. 15, p. 463.

ANDRADE, S. C. D. P.; CORRÊA, J. A. D. J. Estimativa do Saldo de Radiação Instantâneo à Superfície para a Cidade de Santarém - PA, Através de imagens do Landsat 5-TM. Revista Brasileira de Geografia Física, 07, n. 4, 653 $661,2014 .$.

ANJOS, M. W. B. D.; GANHO, N.; ARAÚJO, M. D. Uma Análise dos contrastes Topoclimáticos no Espaço Urbano e Periurbano de Aracau/SE: Os Campos Térmicos e Higrométricos. Revista Brasileira de Climatologia, 13, n. 298 - 318, Jul/Dez, 2013.

BETTS, A. K. ; FISCH, G. ; VON RANDOW, C. ; SILVA DIAS, M. A. F. ; COHEN, J. C. P. ; DA SILVA, R. ; FITZJARRALD, D. R. The amazonian boundary layer and mesoscale circulations. In: KELLER, M., et al. Amazonia and Global Change. Washington: American Geophysical Union, v. 186, Cap. 11, p. 565, $2009 .$.

BIUDES, M.S.; NOGUEIRA, J.S.; DALMAGRO, H.J.; MACHADO, N.G.; DANELICHEN, V.H.M.; SOUZA, M.C. Mudança no microclima provocada pela conversão de uma floresta de cambará em pastagem no norte do Pantanal. Revista de Ciências Agro-Ambientais, v.10, p.61-68, 2012.

BIUDES, M.S.; MACHADO, N.G.; DANELICHEN, V.H.M.; SOUZA, M.C.; VOURLITIS, G.L.; NOGUEIRA, J.S. Ground and remote sensing-based measurements of leaf area index in a transitional forest and seasonal flooded forest in Brazil. International Journal of Biometeorology, v.58, v.6., p.1181$1193,2014$.

BIUDES, M. S; VOURLITIS, G. L.; MACHADO, N. G.; DE ARRUDA, P. H. Z.; NEVES, G. A. R.; LOBO, F. DE A.; NEALE, C. M. U.; NOGUEIRA, J. S. Patterns of energy exchange for tropical ecosystems across a climate gradient in Mato Grosso, Brazil. Agricultural and forest Meteorology, v.202, p.112 - 124, 2015.

CORINGA , E. A. O.; COUTO, E. G.; PEREZ, X. L. O.; TORRADO, P. V. Atibutos de solos hidormóficos no Pantanal Norte Mato-Grossense. Acta Amazônica, v.42, n. 1, p. $465-472,2012$.

CPTEC/INPE. CLIMANÁLISE - BOLETIM DE MONITORAMENTO E ANÁLISE CLIMÁTICA. CENTRO DE PREVISÃO DO TEMPO E ESTUDOS CLIMÁTICOS. CACHOEIRA PAULISTA - SP. 2014.

CUI, Y. P.; LIU, J. Y.; HU, Y. F.; WANG, J. B.; KUANG, W. H. Modeling the radiation Balance of Different Urban Underlying Surfaces. Chinese Science Bulletin, v.57, n. 9, p. 1046 - 1054, 2012.

ESCOBAR, G. C. J. Padrões de circulação em superfície e em 500 hpa na américa do sul e eventos de anomalias positivas de precipitação no estado de minas gerais durante o mês de dezembro de 2011. Revista Brasileira de Meteorologia, v.29, n. 1, p. 105 - 124, 2014d.

ESCOBAR, G. C. J. Síntese Sinótica Do Mês de Julho De 2014. CPTEC/INPE. Cachoeira Paulista-SP, p. 13. 2014c. 
ESCOBAR, G. C. J. Síntese Sinótica Do Mês De Maio de 2014. CPTEC/INPE. Cachoeira Paulista-SP, p. 11. 2014a.

ESCOBAR, G. C. J. Síntese Sinótica Do Mês de Junho De 2014. CPTEC/INPE. Cachoeira Paulista-SP, p. 13. 2014b.

GIONGO, P. R.; MOURA, G. B. .A.; SILVA, B. B.; DA ROCHA, H. R.; MEDEIROS, S.R.R.; NAZARENO, A. C. Albedo à Superfície a Partir de Imagens Landsat 5 em Áreas de Cana-de-Açúcar e Cerrado. Revista Brasileira de Engenharia Agrícola e Ambiental, v.14, n. 3, p. 279 - 287, 2010.

GOMES , H. B.; DA SILVA , B. B.; CAVALCANTI, E. P.; DA ROCHA, H. R. Balanço de Radiação em Diferentes Biomas no Estado de São Paulo Mediante Imagens Landsat 5. Geociências, 28, n. 2, p.153 - 164, 2009.

GPT. Síntese Sinótica Do Mês De Fevereiro De 2014. CPTEC/INPE. Cachoeira Paulista-SP, p. 14. 2014.

GU, L.; FUENTES, J. D.; GARSTANG, M.; SILVA, J. T.; HEITZ, R. ; SINGLER, J. Cloud modulation of surface solar irradiance at a pasture site in southern Brazil. Agricutural and Forest Meteorology, v. 106, p.117 - 129, 2001.

GUSMÃO, ANA C.V.L.; DA SILVA, BERNARDO B.; MONTENEGRO, SUZANA M. G. L. ; GALVÍNCIO, JOSICLÊDA D. Determinação do Salso radiativo na Ilha do Bananal, TO, com Imagens Orbitais. Revista Brasileira de Engenharia Agrícola e Ambiental, v. 16, n. 10, p. 1107 - 1114, 2012.

INAMDAR, A. K.; GUILLEVIC, P. C. Net Surface Shortwave Radiation from GOES Imagery - Product Evaluation Using Ground-Based Measurements from SURFRAD. Remote Sensing, v. 7, n. 8, 10788 - 10814, 2015.

IQBAL, M. An indroduction to solar radiation. Vancouver: AP., 1983. 389 p.

JUNK, W.J.; NUNES DA CUNHA, C. Pantanal: A large South American wetland at a crossroads. Ecological Engineering, v.24, p.391-401, 2005.

KUSHARI, B.; KANITPONG, K. Surface Albedo of Bangkok Roads. Proceedings of the Eastern Asia Society for Transportation Studies, v. 8, 2011.

MACHADO, N. G.; BIUDES, M. S.; ANGELINI, L. P.; MÜTZENBERG, D. M. S.; NASSARDEN, D. C. S.; BILIO, R. DE S.; DA SILVA, T. J. A.; NEVES, G. A. R.; ARRUDA, P. H. Z.; NOGUEIRA, J.S. Sazonalidade do balanço de energia e evapotranspiração em área arbustiva alagável no Pantanal mato-grossense. Revista Brasileira de Meteorologia, v. 31, n1, p. 82 - 91, 2016.

MACHADO, N. G.; BIUDES, M. S.; QUERINO, C. A. S.; DANELICHEN, V. H. M.; VELASQUE, $M$. C. S. SEASONAL AND INTERANNUAL PATTERN OF METEOROLOGICAL VARIABLES IN CUIABÁ, BRAZIL. Revista Brasileira de Geofísica, v. 33, n. 3, p. 1-23, 2015.

MACHADO, N. G.; SANCHES, L.; SILVA, L. B.; NOVAIS, J. W. Z.; AQUINO, A. M.; BIUDES, MARCELO SACARDI; PINTO-JUNIOR, O. B.; NOGUEIRA, J. S. Soil nutrients and vegetation structure in a neotropical seasonal wetland. Applied Ecology and Environmental Research, v. 13, p. 289 - 305, 2015.

MARENGO, J. A. ; NOBRE, C. A. ; SElUCHI, M. E. ; CUARTAS , A. ; ALVES , L. M. ; MENDIONDO, E. D. ; OBREGÓN, G. ; SAMPAIO , G. A seca e a crise hídrica de 2014 - 2015 em São Paulo. Revista USP, v. 116, p.31 - 44, 2015. 
MOURA, M. A. L.; LYRA, R. F. F.; BENINCASA, M.; DE SOUZA, J. L.; NASCIMENTO FILHO, M. F. Variação do Albedo em Áreas de Floresta e Pastagem na Amazônia. Revista Brasileira de Agrometeorologia, Santa Maria, v. 7, n. 2, p. 163 - 168, 1999.

NEVES, T. T. A. T.; FISCH, G.. Camada limite noturna sobre área de pastagem na Amazônia. Revista Brasileira de Meteorologia, v. 26, n. 4, p. 619 - 628, 2011.

OLIVEIRA, F. N. M. Climatologia de bloqueios atmosféricos no Hemisfério Sul: obsrevações, simulações do Icima do séculoo XX e cenários futuros de mudanças climáticas. São Paulo: Instituto de Astronomia, Geofísica e Ciências Atmosféricas, 2011. 158 p. Tese de Doutorado.

OLIVEIRA, F. N. M.; CARVALHO, L. M. V.; AMBRIZZI, T. A New Climatology for Southern Hemisphere Blockings in the Winter and the Combined Effect of ENSO and SAM Phases. International Journal of Climatology, v. 34, n. 5, p. 1676 $1692,2014$.

PAVÃO, V. M.; QUERINO, C. A. S.; BENEDITTI, C. A.; PAVÃO, L. O.; QUERINO, J. K. A. DA SILVA; MACHADO, N. G.; BIUDES, M. S. Temperatura e Albedo da Superfície por Imagens Tm Landsat 5 em diferentes usos do Solo no Sudoeste da Amazônia Brasileira. Revista Brasileira de Climatologia, v. 16, p. 169 - 183, Jan/Jun, 2015.

QUERINO, C. A. S.; BENEDITTI, C. A.; MACHADO, N. G.; DA SILVA, M. J. G.; QUERINO, J. K. A. S.; SANTOS NETO, L. A.; BIUDES, M. S. Spatiotemporal NDVI, LAI, Albedo, and Surface Temperature Dynamics in the Southwest of the Brazilian Amazon Forest. Journal of Applied Remote Sensing, v. 10, n. 2, p. 026007-1 - 026007-12, 2016.

QUERINO, C. A. S.; MOURA, M. A. L.; LYRA, R. F. F.; MARIANO, G. L. Avaliação e Comparação de Radiação Solar Global e Albedo com Ângulo Zênital na Região Amazônica. Revista Brasileira de Meteorologia, v. 21, n. 3a, p. 42 - 49, 2006.

QUERINO, C. A. S.; MOURA, M. A. L.; QUERINO, J. K. A. S. Impacto do Desmatamento de uma Área de Mangue no Albedo Superficial. Revista Brasileira de Meteorologia, v. 28, n. 4, p. 401 - 408, 2013.

QUERINO, C. A. S.; MOURA, M. A. L.; QUERINO, J. K. A. S.; VON RADOW, C.; MARQUES FILHO, A. O. Estudo da Radiação Solar Global e do Índice De Transmissividade (Kt), Externo e Interno, em uma Floresta de Mangue em Alagoas - Brasil. Revista Brasileira de Meteorologia, v. 26, n. 2, p. 204 - 214, 2011.

SANCHES - ROMERO, A.; SANCHES - LORENZO , A.; CALBÓ, J. ; CONZÁLES, J. A. ; MOLINA - AZONIN, C. The signal of aerossol-induced changes in sunshine duraction records: A review of the evidence. Journal of Geophysical Research Atmospheres, p. 4657 - 4673, 2014.

SOUZA, J. L.; NICÁCIO, R. M.; MOURA, M. L. L. Global Solar Radiation Measurements in Maceió, Brazil. Renewable Energy, v. 30, p. 1203 - 1220, 2005.

WMO. Manual on the Global Observing System. World Meteorologica Organization. Geneva, p. 50. 2003. (ISBN 92-63-13544-4). 